\title{
Prevalence of Tobacco Use and Its Associated Factors among School Going Adolescents in Birgunj Sub-Metropolitan, Nepal
}

\author{
${ }^{1}$ Arbind Kumar Chaudhary, ${ }^{1}$ Tulsi Ram Bhandari \\ ${ }^{1}$ School of Health and Allied Sciences, Pokhara University, Kaski, Nepal
}

\begin{abstract}
Tobacco use means consumption of any form of tobacco products either smoked or smokeless. Common used tobacco products are cigarette, cigars, pipe tobacco and favored Sisha tobacco, Surti/khaini, Panmasala, and Gutkha. It is one of the major causes of preventable mortality and morbidity worldwide. Objective of the study was to assess the prevalence of tobacco use and its associated factors among higher secondary school going adolescents of Birgunj Sub-metropolitan, Nepal. A schools based cross-sectional descriptive study was carried out using self-administrative questionnaire and it was prepared based on Global Youth Tobacco Survey. It was developed and validated for assessing the tobacco use among adolescents. Amongst 16 higher secondary schools, three public and three private schools were selected randomly. Similarly required sample (307) were recruited as proportionately from each school considering number of students studying in each selected school from August to December 2016. Prevalence of ever use of tobacco was $15.6 \%$. Cigarette was the most (70.8\%) commonly used as tobacco product. The average age of initiation of tobacco use was 13.96 \pm+2.62 year. More than half (52.1\%) of the tobacco users purchased tobacco from shops. Peer pressure (45.8\%) was one of the major influencing factors of ever use of tobacco. Age, gender, friends pressure and parent's education were found significantly associated with ever use of tobacco among students. Nearly one-fifth adolescents used some type of tobacco products in last six month. Tobacco used by parents, peers and others family members at home and public places, and easy access of tobacco products were the major influencing factors of tobacco use among students. School and community based awareness programs and tobacco control legislations should be implemented consistently to control and discourage the consumption of tobacco products.
\end{abstract}

Keywords: Adolescents, students, associated factors, tobacco use

Corresponding address: Tulsi Ram Bhandari, PhD, School of Health and Allied Sciences, Pokhara University,

E-mail: tulsib2004@gmail.com

\section{INTRODUCTION}

The dried leaves of the tobacco are processed into various tobacco products such as Cigarette, Cigars, Pipe tobacco and Flavored Sisha. It can be smoked, chewed or snuffed through nose. ${ }^{1}$ Adolescent is a period between ages 10-19 years in which physical, psychological and social maturity occur among most boys and girls. In Nepal, adolescences constitute nearly $22 \%$ of the total population. ${ }^{2}$

Tobacco use is major cause of preventable mortality and morbidity. Every year nearly five million people die from tobacco use worldwide. It is expected that the figure will increase up to 10 million in the next 20-30 years. Among all deaths occurred by tobacco, 70\% deaths are occur in developing countries. ${ }^{3,4}$ Most influencing factors of tobacco use among adolescences are the behavior, attitude, and imitation of parents and peer groups. ${ }^{5}$

It is estimated that globally 100 million people died by tobacco used in $20^{\text {th }}$ century. Every year 5.4 million people die globally due to tobacco used. It is also expected that the figure will rise eight million per year by the year 2030 . Among the deaths more than $80 \%$ occur in developing countries. ${ }^{6}$ A study shows that $7.2 \%$ of adolescent students smoked cigarettes in Kenya. ${ }^{7}$
Both smoking and smokeless form of tobacco used among adolescences was quit high in South East Asia. ${ }^{8}$ Global Adult Tobacco Survey (GATS) showed that smoking tobacco was common among adult males, while smokeless tobacco was more common among females in South East Asian Region. ${ }^{9}$ It further suggested that the exposed rate of smoking is higher among males (33.5\%) compared with females $(11.9 \%)$ age between $13-15$ years. ${ }^{10}$

Global Youth Tobacco Survey (GYTS), Nepal (2001) had reported $16.3 \%$ prevalence of tobacco use among the high school students ${ }^{11}$ and GYTS, Nepal (2011) revealed that $10 \%$ of student currently use any form of tobacco, nine percent currently use smoked tobacco product and $16.2 \%$ use smokeless tobacco product currently. In Terai region of Nepal, tobaccos are using in various forms of smoked and smokeless tobaccos. Smoking form of tobacco are Bidis, Cigarettes, or using by device like Hooka, Chillum. Smokeless form of tobacco includes Khaini/Surti, Gutkha, Zarda, snuff and as ingredients of Paan masala. ${ }^{4}$ This study aims to examine the prevalence of tobacco use and factors associated among higher secondary school adolescences of Birgunj Sub-metropolitan, Parsa, Nepal. 


\section{METHODS}

This study was a school based cross-sectional descriptive study conducted in Birgunj Sub-metropolitan from August to December 2016. The sample size was calculated using this formula $Z \alpha^{2} \mathrm{pq} / \mathrm{d}^{2}$, at $95 \%$ confidence limit at permissible error $5 \%$, prevalence of ever use of tobacco product was $25.3 \%{ }^{4}$ and non response rate $10 \%$. The sample size of the study was fixed 322 adolescents from higher secondary schools of Birgunj sub-metropolitan including non-response rate. We divided all 16 schools into two groups i.e. public and private, and selected equal three schools from each group using simple random sampling method. We further chose one class from each selected school randomly and selected all students of selected class in this study. Ethical clearance was obtained from the Institutional Review Committee (IRC) of Pokhara University. We also obtained written permission from each school administration before initiating the study.

Data were collected using a self-administrative questionnaire and it was prepared based on GYTS. We adopted this questionnaire and translated in Nepali language. The translated Nepali version of questionnaire was pre-tested among the adolescent students of another school of Birijanj which was not included in this study. After pre-test, it is modified and made understandable what intended to be measured. Proper instruction was given to all participants, how to fill the questionnaire. We informed all students for providing accurate information as much as possible considering their real practices. We assured all participates for maintaining confidentiality. We also requested staff and teachers not to be present in the class during the administration of the questionnaire for creating more comfortable environment to respond accurately.

Use of tobacco among adolescent students was considered as the dependent variable while age, sex, gender, ethnicity, religion, type of school, availability of tobacco products, education level of parents, tobacco used by family members and friends and knowledge about the adverse effect of tobacco use were dependent variables. The collected data from different schools were checked and filed separately for preventing loss and misuse. First, we verified all collected data for completeness and consistency. Then we coded al data and entered in EPI DATA Version 3.1 and all the entered data were transferred into software Statistical Package for Social Science (SPSS version 21) for further analyses. We performed descriptive and inferential statistical analysis considering the objective of the study. We applied chisquare test for establishing associated factors with tobacco use among adolescences.

\section{RESULTS}

\section{Demographic characteristics of respondents}

Out of 322 self-administered questionnaires only 307 were meet our criteria and we decided to use only these 307 questionnaires for further analysis. Out of 307 adolescent students, more than half respondents $(54 \%)$ were from the government schools and (46\%) from private schools. About two-thirds $(64.8 \%)$ of respondents were late adolescences of the age group 17 to 19 years. The mean age of the adolescences was $16.19 \pm 1.52$. Nearly equal proportion of males $(51.47 \%)$ and females $(48.53 \%)$ were participated in the study. Among the respondents by religion, $88.3 \%$ were Hindu followed by Muslim 10.4\% and Buddhist $1.3 \%$. More than half (59\%) respondents were belonged to disadvantaged non-Dalit-Terai caste and rest other disadvantaged Janajatis (16.6\%), relatively minorities (10.1\%), upper caste $(7.5 \%)$ and relatively advantaged Janajatis $(2.9 \%)$. The details of demographic characteristics of the respondents are presented in Table 1.

Table 1: Demographic characteristics of respondents $(\mathbf{n}=\mathbf{3 0 7})$

\begin{tabular}{|c|c|c|}
\hline Characteristics & Number & Percent \\
\hline \multicolumn{3}{|l|}{ Age (years) } \\
\hline Early adolescent (10-13) & 8 & 2.6 \\
\hline Middle adolescent (14-16) & 100 & 32.6 \\
\hline Late adolescent (17-19) & 199 & 64.8 \\
\hline \multicolumn{3}{|l|}{ Mean $=16.19(\mathrm{SD}= \pm 1.523)$} \\
\hline \multicolumn{3}{|l|}{ Gender } \\
\hline Male & 158 & 51.5 \\
\hline Female & 149 & 48.5 \\
\hline \multicolumn{3}{|l|}{ Types of school } \\
\hline Government & 167 & 54.4 \\
\hline Private & 140 & 45.6 \\
\hline \multicolumn{3}{|l|}{ Level of school } \\
\hline Secondary & 182 & 59.3 \\
\hline Higher Secondary & 125 & 40.7 \\
\hline \multicolumn{3}{|l|}{ Ethnicity } \\
\hline Dalit & 12 & 3.9 \\
\hline Disadvantage Janajatis & 51 & 16.6 \\
\hline Disadvantaged non-Dalit Terai caste & 181 & 59 \\
\hline Relatively minorities & 31 & 10.1 \\
\hline Relatively advantaged Janajatis & 9 & 2.9 \\
\hline Advantaged caste & 23 & 7.5 \\
\hline \multicolumn{3}{|l|}{ Religion } \\
\hline Hindu & 271 & 88.3 \\
\hline Muslim & 32 & \begin{tabular}{|l|}
10.4 \\
\end{tabular} \\
\hline Buddhist & 4 & 1.3 \\
\hline
\end{tabular}

Considering parents education status, $11.1 \%$ of fathers and $30.6 \%$ of mothers were illiterate. Most parents completed secondary education i.e. $41 \%$ of fathers and $33.5 \%$ of mothers. Majority of fathers (41\%) and mothers (33.5\%) had completed secondary education. Nearly half (44.3\%) fathers involved in job followed by business (33.9\%) and farming (21.8). one-fourth $(75.22 \%)$ of the respondent's 
mother were housewife. The details of parents' education and occupation are given in Table 2.

\section{Socio-economic characteristics}

Table 2: Socio economic characteristics of respondents $(n=307)$

\begin{tabular}{|l|l|l|}
\hline \multicolumn{1}{|c|}{ Characteristics } & Number & \multicolumn{1}{c|}{ Percent } \\
\hline Father's education & & \\
\hline Illiterate & 34 & 11.1 \\
\hline Primary & 24 & 8.8 \\
\hline Lower secondary & 33 & 12.1 \\
\hline Secondary & 112 & 41 \\
\hline Higher secondary & 63 & 23.1 \\
\hline Bachelor and above & 41 & 15.0 \\
\hline Mother's education & & \\
\hline Illiterate & 94 & 30.6 \\
\hline Primary level & 49 & 23 \\
\hline Lower secondary level & 65 & 30.5 \\
\hline Secondary level & 71 & 33.3 \\
\hline Higher secondary level & 21 & 9.9 \\
\hline Bachelor level & 7 & 3.3 \\
\hline Father's occupation & & \\
\hline Business & 104 & 33.9 \\
\hline Job & 136 & 44.3 \\
\hline Farmer & 67 & 21.8 \\
\hline Mother's occupation & & \\
\hline Business & 20 & 6.5 \\
\hline Job & 30 & 9.8 \\
\hline Farmer & 26 & 8.5 \\
\hline Housewife & 231 & 75.2 \\
\hline
\end{tabular}

Prevalence of ever use of tobacco and its associated factors

Nearly 16\% adolescences ever use any type tobacco products. Out of tobacco users, more than two thirds used smoking tobacco and remaining used chewing tobacco. Average age of initiation of ever use of tobacco was 13.96 \pm \pm 2.62 . Nearly half (47.9\%) of the adolescents initiated tobacco used during middle adolescent period. Among them one-third (33.3\%) of the respondents were occasional user and $(27 \%)$ respondents were regular user of tobacco.

Table 3: Related factors for using tobacco

\begin{tabular}{|c|c|c|}
\hline Associated factors & Number & Percent \\
\hline \multicolumn{3}{|l|}{ Ever use of tobacco } \\
\hline Yes & 48 & 15.6 \\
\hline No & 259 & 84.4 \\
\hline \multicolumn{3}{|l|}{ Influence to initiate tobacco use } \\
\hline Peer pressure & 22 & 45.8 \\
\hline For experience & 16 & 33.3 \\
\hline Imitating & 10 & 20.8 \\
\hline \multicolumn{3}{|c|}{ Knowledge about adverse effect of tobacco use } \\
\hline Yes & 282 & 91.9 \\
\hline \multicolumn{3}{|c|}{ Tobacco used by family members and friends } \\
\hline Father & 126 & 41.0 \\
\hline Mother & 3 & 1.0 \\
\hline Any other family member & 56 & 18.2 \\
\hline Friends & 80 & 26.1 \\
\hline \multicolumn{3}{|c|}{ Expose to tobacco advertisements in last 30 days } \\
\hline Yes & 17 & 5.5 \\
\hline
\end{tabular}

Factors associate with tobacco use

Table 4: Association between socio-demographic characteristics and ever use of tobacco

\begin{tabular}{|c|c|c|c|c|c|}
\hline \multirow{2}{*}{\multicolumn{2}{|c|}{ Characteristics }} & \multicolumn{2}{|c|}{ Ever use of tobacco } & \multirow{2}{*}{$\chi^{2}$ value } & \multirow{2}{*}{ p-value } \\
\hline & & Yes & \begin{tabular}{|l|} 
No \\
\end{tabular} & & \\
\hline \multicolumn{6}{|l|}{ Sex } \\
\hline & Male & $46(29.1 \%)$ & $112(70.9 \%)$ & $44.84 \#$ & \multirow{2}{*}{$<0.001^{* * *}$} \\
\hline & Female & $2(1.3 \%)$ & $147(98.7) \%$ & & \\
\hline \multicolumn{6}{|c|}{\begin{tabular}{l|l} 
Age & \\
\end{tabular}} \\
\hline & $10-13$ years & $1(12.5 \%)$ & $7(87.5 \%)$ & & \multirow{3}{*}{$<0.001^{* * *}$} \\
\hline & $14-16$ years & $5(5 \%)$ & $95(95 \%)$ & $15.37 \#$ & \\
\hline & $17-19$ years & $42(21.1 \%)$ & $157(78.9 \%)$ & & \\
\hline \multicolumn{6}{|c|}{ Type of school } \\
\hline & Government & $28(16.8 \%)$ & $139(83.2 \%)$ & & \multirow{2}{*}{0.551} \\
\hline & Private & $20(14.3 \%)$ & $120(85.7 \%)$ & 0.36 & \\
\hline \multicolumn{6}{|c|}{ Ethnicity } \\
\hline & \begin{tabular}{|l} 
Dalit and \\
disadvantaged \\
groups
\end{tabular} & $42(15.7)$ & $225(84.3)$ & 0.28 & \multirow[t]{2}{*}{1.151} \\
\hline & Advantaged groups & $9(22.5)$ & $31(77.5)$ & & \\
\hline \multicolumn{5}{|c|}{ Religion } & \multirow{3}{*}{0.321} \\
\hline & Hindu & $41(15.1 \%)$ & $230(84.9 \%)$ & 2.27 & \\
\hline & Non-Hindu & $7(21.9 \%)$ & $25(78.1 \%)$ & & \\
\hline \multicolumn{6}{|c|}{ Peer's influence on tobacco use } \\
\hline & Yes & $39(48.8 \%)$ & $41(51.2 \%)$ & 89.95 & \multirow{2}{*}{$<0.001^{* * *}$} \\
\hline & No & $9(4 \%)$ & $218(96 \%)$ & & \\
\hline
\end{tabular}

*** $p$ value significant at $<0.001$ \# likelihood ratio

Amongst various factors sex, $\left(\chi^{2}=44.838, \mathrm{p}\right.$ value $\left.<0.001\right)$, age $\left(\chi^{2}=15.371, \mathrm{p}\right.$ value $\left.<0.001\right)$ and peers' influence $\left(\chi^{2}\right.$ $=89.946, \mathrm{p}$ value $<0.001)$ were found statically significant.

\section{DISCUSSION}

The prevalence of ever use of tobacco among students was $15.6 \%$ which was comparatively higher than the Global Youth Tobacco Survey (GYTS) Nepal 2011 findings (10\%). The prevalence of ever use of tobacco varied in different parts of Nepal i.e. Dharan (19.7\%), Pokhara (47.1\%), Kalaiya $(25.3 \%)$ and $(13.9 \%)$ among junior collegiate of western Nepal. ${ }^{4,8,12,13}$ The prevalence of smoking among adolescencents was high in African countries i.e. Sierra Leone, Lesotho and Madagascar compared with the findings of this study. ${ }^{14}$

In Birganj Sub- metropolitan the use of tobacco was found higher among the adolescent students of government schools compared to private schools. A study showed different findings in Pokhara Nepal whereas ever use of tobacco was higher among adolescent students of private schools. This might be due to good financial status of the parents of private school students compared with parents of public school students. ${ }^{8}$ The average age of initiation of tobacco use was 13.96 year which was found to be in consistency with studies in Kaski, Dharan and Iran, whereas the mean age of onset were 16, 14, 12 and 17.5 respectively. ${ }^{8,12,15,16}$

The prevalence of ever used of tobacco was not found significant different among disadvantaged and advantaged 
groups which was similar to the finding Nepal Adolescent and Youth Survey in 2010. ${ }^{17}$ Cigarette was common used tobacco (70.8\%) among adolescent students which is similar to the findings of a study conducted among the college students in Kathmandu valley and North Carolina. ${ }^{13,18}$ Nearly one-fifth students used chewing tobacco i.e. Pannmasala and Gutkha of various brands which was higher than Kaliaya district of Nepal. ${ }^{4}$

More than half tobacco users adolescences obtained tobacco from retail-markets and remaining got from their relatives and friends which was similar to the findings of a study in Dharan of Eastern Nepal. ${ }^{8}$ The ever use of tobacco was higher among male students compared to female students which was comparable with the findings

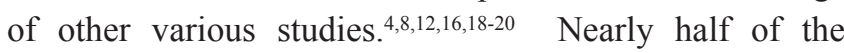
ever tobacco users were influenced from their friends. The ever use of tobacco and peers' influence was found significant associated each other. During adolescent period, the relationship of peer groups is stronger and thus they are influenced more by friends. Similar results were showed other studies in Kathmandu valley. ${ }^{13,21}$ Very few adolescent students reported that they were exposed to tobacco advertisement in media and event during the last 30 days. However the advertisement of tobacco product is banded in national electronic media. A study showed strong evidence of association between viewing smoking in movie and initiation of smoking among Indian adolescences. ${ }^{22}$ GYTS in United State 2011-2013 reported that youth who were exposed to tobacco advertisements had higher rate of initiation of smoking. ${ }^{23}$ Data from Demographic and Health Survey (DHS) conducted in nine countries from 2004 to 2011 found positive association between smoking and media utilization. ${ }^{24}$

Despite the schools based cross-sectional study, this study shows only reported quantitative information. Among bulk of research tools, we only used self-administrative questionnaire, so there was chance of false reporting of the information. Similarly, due to constraints of time and resources, we only took minimum required sample size.

\section{CONCLUSIONS}

Tobacco consumed by school going adolescents is a remarkable problem in Birganj Sub-metropolitan whereas nearly one-fifth adolescencents used some type of tobacco in last six months. Tobacco used by parents, peers and others family members at home and public places, and easy access of tobacco products were the major influencing factors of tobacco use among adolescent students. School and community based awareness programs and tobacco control legislations should be implemented consistently to control and discourage the consumption of tobacco and cessation of tobacco in Birganj Sub-metropolitan Nepal.

\section{ACKNOWLEDGEMENTS}

We thank all respondents, Schools and District Education office parsa for their participation, cooperation and permission for this study.

\section{REFERENCES}

1. Jacobs M. From the First to the Last Ash: The History, Economics \& Hazards of Tobacco: a Comprehensive Adult Basic Education Curriculum. Community Learning Center, 1997.

2. Family Health Division. National Adolescent Health and Development Strategy. Nepal, Kathmandu, Department of Health Services Ministry of Health His Majesty's Government, 2000.

3. Abdullah AS, Stillman FA, Yang L, Luo H, Zhang Z, Samet JM. Tobacco use and smoking cessation practices among physicians in developing countries: a literature review (1987-2010). Int J Environ Res Public Health, 2013; 11:429-55.

4. Bhaskar RK, Sah MN, Gaurav K, Bhaskar SC, Singh R, Yadav MK, et al. Prevalence and correlates of tobacco use among adolescents in the schools of Kalaiya, Nepal: a cross-sectional questionnaire based study. Tob Induc Dis, 2016; 14:11.

5. Charrier L, Berchialla P, Galeone D, Spizzichino L, Borraccino A, Lemma P, et al. Smoking habits among italian adolescents: what has changed in the last decade? BioMed Rse Int, 2014; 2014:287139.

6. Binu V, Subba S, Menezes R, Kumar G, Ninan J, Rana M, et al. Smoking among Nepali youth-prevalence and predictors. Asian Pac J Cancer Prev, 2010;11:221-6.

7. Reda AA, Moges A, Yazew B, Biadgilign S. Determinants of cigarette smoking among school adolescents in eastern Ethiopia: a cross-sectional study. Harm reduction J, 2012; 9:1.

8. Pradhan PMS, Niraula SR, Ghimire A, Singh SB, Pokharel PK. Tobacco use and associated factors among adolescent students in Dharan, Eastern Nepal: a cross-sectional questionnaire survey. BMJ open, 2013; 3:002123.

9. Sinha DN, Palipudi KM, Rolle I, Asma S, Rinchen S. Tobacco use among youth and adults in member countries of SouthEast Asia region: review of findings from surveys under the Global Tobacco Surveillance System. Ind J public health, 2011; 55:169-76.

10. Borgan SM, Jassim G, Marhoon ZA, Almuqamam MA, Ebrahim MA, Soliman PA. Prevalence of tobacco smoking among 
health-care physicians in Bahrain. BMC Public Health, 2014; 14:931.

11. Sreeramareddy CT, Kishore P, Paudel J, Menezes RG. Prevalence and correlates of tobacco use amongst junior collegiates in twin cities of western Nepal: a cross-sectional, questionnaire-based survey. BMC Public Health, 2008; 8:1.

12. Paudel D. Tobacco use among adolescent students in secondary schools of Pokhara sub metropolitan city of Nepal: TU Kathmandu, 2003.

13. Aryal UR, Deuba K, Subedi A, and SR, Laxmi B. Prevalence and Determinants of Cigarette Smoking among the College Students of Kathmandu Valley. Asian J Medical Sciences, 2010.

14. Sreeramareddy CT, Pradhan PM, Sin S. Prevalence, distribution, and social determinants of tobacco use in 30 sub-Saharan African countries. BMC medicine, 2014;12:243.

15. Mousawi AA. The prevalence of smoking among karbala/iraq university students in iraq in 2005. Tobacco use insights, 2014; 7:9-14.

16. Sreeramareddy CT, Kishore P, Paudel J, Menezes RG. Prevalence and correlates of tobacco use amongst junior collegiates in twin cities of western Nepal: a cross-sectional, questionnaire-based survey. BMC Public Health, 2008; 8:97.

17. Government of Nepal. Nepal Adolescent and Youth Survey 2010/11 Highlights. 2011.

18. Kowitt SD, Patel T, Ranney LM, Huang LL, Sutfin EL, Goldstein AO. Poly-tobacco use among high school students. Int J Environ Res Public Health, 2015 Nov; 12:14477-89.

19. Moradi-Lakeh M, El Bcheraoui C, Tuffaha M, Daoud F, Al Saeedi M, Basulaiman M, et al. Tobacco consumption in the Kingdom of Saudi Arabia, 2013: findings from a national survey. BMC Public Health, 2015;15:611.

20. Sreeramareddy CT, Ramakrishnareddy N, Harsha Kumar H, Sathian B, Arokiasamy JT. Prevalence, distribution and correlates of tobacco smoking and chewing in Nepal: a secondary data analysis of Nepal Demographic and Health Survey-2006. Subst Abuse Treat Prev Policy, 2011; 6:33.

21. Aryal UR . Smoking susceptibility and intention to smoke among secondary school adolescents in Nepal. J Nepal Health Res Counc, 2015;13: 26-30.

22. Arora M, Mathur N, Gupta VK, Nazar GP, Reddy KS, Sargent JD. Tobacco use in bollywood movies, tobacco promotional activities and their association with tobacco use among Indian adolescents. Tobacco control, 2012; 21(:482-7.

23. Bunnell RE, Agaku IT, Arrazola RA, Apelberg BJ, Caraballo RS, Corey CG, Intentions to smoke cigarettes among neversmoking US middle and high school electronic cigarette users: NYTS, 2011-2013. Nicotine \& tobacco research : Off J Society for Res on Nicotine and Tobacco, 2015;17:228-35.

24. Achia TN. Tobacco use and mass media utilization in sub-Saharan Africa. PLoS One, 2015;10:0117219. 